\title{
Somatostatin analogues inhibit cancer cell proliferation in an SSTR2-dependent manner via both cytostatic and cytotoxic pathways
}

\author{
YI ZOU, XIAOPING XIAO, YUEQIN LI and TIANHONG ZHOU \\ School of Life Science and Technology, Jinan University, Guangzhou 510632, P.R. China
}

Received July 1, 2008; Accepted August 28, 2008

DOI: $10.3892 /$ or_00000233

\begin{abstract}
Somatostatin receptors (SSTRs) are inhibitory G-protein coupled receptors that are ubiquitously expressed in normal and cancer cells. Somatostatins (SST) are the natural ligands for SSTRs and act as inhibitory regulators of hormone secretion and proliferation. Octreotide and RC-160 (vapreotide) are two well tolerated SSTR2/SSTR5 selective somatostatin analogues (SSA) that have been used in the treatment of cancers with mixed outcomes. Loss-of-expression of SSTR2 in tumor tissues has been suggested to correlate to tumor progressions and to the poor outcomes of somatostatin analogue treatment in certain clinical trials. In this study, exogenous human SSTR2 was overexpressed in two cancer cell lines, capan-2 cells and A549 cells, which had different profiles of endogenous SSTR expression. It was shown that overexpression of SSTR2 dramatically inhibited the proliferation of SSTR2-positive and SSTR2-negative cancer cells. Further growth inhibition of these cancer cells overexpressing SSTR2 was observed by application of octreotide/ $\mathrm{RC}-160$ in a dose-dependent fashion. In addition, immunoassay demonstrated that SSA/SSTR2 inhibited proliferation via both cell cycle arresting and promoting apoptosis. The results suggested that SSTR2 could be a promising candidate for gene therapy for SSTR2-positive and SSTR2-negative tumors. The cellular level of SSTR2 might be a critical factor that could affect both tumor progression and the outcomes of somatostatin analogue treatment.
\end{abstract}

\section{Introduction}

SSTRs (somatostatin receptors) are G-protein coupled plasma membrane receptors with two forms of somatostatin (SST) peptides, SS-14 and SS-28, as their natural ligands (1). The two peptides produced by SST cells act as neurotransmitters

Correspondence to: Dr Tianhong Zhou, Department of Biology, School of Life Science and Technology, Jinan University, Guangzhou 510632, P.R. China

E-mail: tzth@jnu.edu.cn

Key words: somatostatin analogues, somatostatin receptor 2, cancer gene therapy or paracrine/autocrine regulators via five different subtypes of human somatostatin receptors (SSTR1-5), encoded by five distinct SSTR genes segregated on chromosome 14, 16, 17, 20 , and 22 (2-6).

The expression of SSTRs during development is timeand tissue-specific. Inter-species variation and subtypeselective expression have also been shown. In human, expressions of SSTRs have been found in multiple tissues including brain, gut, pituitary, pancreas, adrenals, thyroid and immune cells (7-11). Amongst them, the SSTR2 is the most abundantly expressed subtype. High levels of SSTR2 have been identified in pituitary, islet, adrenals and thymus. Expression of SSTRs has also been demonstrated in most tumors of neuroendocrine origin while found with much lower frequencies in nonendocrine tumors $(12,13)$. Loss-ofexpression of SSTR2 was shown to associate with the metastatic progression of certain tumors such as pancreatic cancers (14). Therefore, SSTR2 has been proposed to be a promising candidate for cancer gene therapy for SSTR2negative tumors (15-17).

In general, activation of SSTRs results in inhibition of cell proliferation and secretion, e.g. pituitary growth hormone and thyroid-stimulating hormone release (18). The influence of SSTR on proliferation came to notice due to the anti-tumor effects observed in those patients who were receiving SST analogue treatment to block secretion of tumors of endocrine origin (19-21). After that, the anti-tumor effect and the clinical application of SST as a potential treatment for cancer have been investigated extensively (22). Some of the results of clinical studies were encouraging, showing improvement of both the quality of life and the survival rate post-SST treatment. Therefore, given the short half-life of SST, SST analogues with much greater metabolic stability and subtypeselectivity have been developed and commonly used in the treatment of SSTR-positive tumors (23-26). Activation of SSTRs in these SSTR-expressing tumors usually resulted in remarkable inhibition of tumor cell proliferation via indirect activities of inhibiting growth hormone secretion and direct activity through SSTR signaling pathways (27). However, the detailed mechanisms of the inhibitory effect of SSTRs are still largely unknown and display both subtype- and cell typeselectivity.

Further investigations have revealed that the SSTRmediated anti-proliferation involve cytostatic (growth arrest) and cytotoxic (apoptotic) actions. Five SSTRs have all been 
indicated in modulating protein tyrosine phosphatase (PTP) activities and in turn, downregulating Ras-MAPK to induce the arrest of cell cycle progression, although certain effects display relative subtype selectivity $(18,28)$. For instance, apoptosis was believed to be triggered via SSTR3 while cell cycle arrest was regulated via MAPK pathway by SSTR1, 2, 4 and 5 (29). Nonetheless, given that multiple SSTRs usually expressed in the same cell, it was suggested that SSTRs were redundant and function in orchestra, instead of as individual functional molecules. Experimental data also indicated that heterodimerization of different subtypes was involved in regulating strength of downstream pathways. For instance, agonist-induced SSTR1/SSTR5 heterodimerization increased their inhibition of adenylylcyclase (30).

Octreotide and RC-160 (vapreotide) are two well tolerated long-acting SST-14 analogues that have been used in clinical practice for $\sim 20$ years with ambiguous outcomes. Both SST analogues display high affinity to SSTR2 and SSTR5 (31). Poor response to SST analogue treatment in certain clinical trials was believed to be relevant to the loss-of-expression of SSTR2 in these patients, although these were rarely assessed. In this study, we investigated the anti-proliferation effect of octreotide and RC-160 in two different cancer cell lines, capan-2 and A549, which showed different profiles of endogenous SSTR expression. In addition, in order to evaluate the potential SST analogue-induced cytostatic and cytotoxic actions, we further investigated the effects of SST analogue treatment on the intracellular levels of cyclin-dependent kinase inhibitor, caspase and Ras-ERK2 (extracellular regulated kinase) signaling. Therefore, the results presented in this study will lead to better understanding of the application of SST analogues and provide insights into the possible mechanisms employed by SSTRs in inhibiting cancer cell proliferation.

\section{Materials and methods}

Materials. Capan-2, a human pancreatic cancer cell line, was a gift from Sun Yat-sen University (Guangzhou, P.R. China) and A549, a human lung cancer cell line, was a gift from Guangzhou Biomedicine Research and Development Centre (Jinan University, Guangzhou, P.R. China). The HEK-293T cells were purchased from Microbix Co. MEM and fetal calf serum (FCS) used in tissue culture were purchased from Invitrogen. 3-[4, 5-dimehyl-2-thiazolyl]-2, 5-diphenyl-2Htetrazolium bromide (MTT), dimethyl sulfoxide (DMSO), penicillin, streptomycin, 5-Bromo-4-chloro-3-indoxyl-ß-Dgalactopyranoside (X-gal) and octreotide were from Sigma. RC-160 was purchased from Genscript. Blue Range ${ }^{\mathrm{TM}}$ prestained protein molecular marker was from Pierce. Goat polyclonal anti-hSSTR2, mouse monoclonal anti-p16, mouse monoclonal anti-caspase-3, rabbit polyclonal anti-ERK-2 and goat polyclonal anti- $\beta$-actin were purchased from Santa Cruz Co. Mouse monoclonal anti-ras was purchased from abcam. The horseradish peroxidase (HRP)-conjugated goat anti-rabbit IgG, rabbit anti-goat IgG and goat anti-mouse IgG were purchased from QED Bioscience.

Propagation of the adenoviral vectors. The recombinated adenoviral vectors encoding full length human SSTR2
(Adv-SSTR2) or Escherichia coli B-galactosidase (Adv-LacZ) were propagated in $293 \mathrm{~T}$ cells and purified using Adeno- $\mathrm{X}^{\mathrm{TM}}$ virus purification kit (Clontech) according to the manufacturer's instruction. The adenoviral vectors were then stored at $-70^{\circ} \mathrm{C}$ before use. Viral titres (PFU) were determined using a modified plaque assay, where $293 \mathrm{~T}$ cells were infected overnight to ensure entry of all functional virions and to avoid confounding by receptor density. The resulting titres for Adv-SSTR2 and Adv-LacZ were $6.3 \times 10^{9} \mathrm{pfu} / \mathrm{ml}$ and $3.2 \times 10^{9} \mathrm{pfu} / \mathrm{ml}$, respectively. These PFU titres (functional virions) were used for dosing in cell transfection.

Cell culture and transfection. To evaluate the transfection efficacies of the adenoviral vectors, $\sim 3 \times 10^{4}$ cells were grown in $1 \mathrm{ml} \mathrm{MEM} \mathrm{(supplemented} \mathrm{with} 100 \mathrm{IU} / \mathrm{ml}$ penicillin, $25 \mathrm{~g} / \mathrm{ml}$ streptomycin, and 10\% FCS) in 24-well microtiter plates and maintained overnight $\left(\sim 80 \%\right.$ confluency) at $37^{\circ} \mathrm{C}$ in a humidified atmosphere containing $5 \% \mathrm{CO}_{2}$. Briefly, the cells were washed with phosphate-buffered saline (PBS), then transfected with Adv-SSTR2 or Adv-LacZ in $200 \mu 1$ serum-free MEM at the density of a multiplicity of infection (MOI) of 100 for $3 \mathrm{~h}$ in a humidified $37^{\circ} \mathrm{C}$ atmosphere containing $5 \% \mathrm{CO}_{2}$. The cells were cultured for additional $48 \mathrm{~h}$ and the LacZ gene expression was visualized by staining for $\beta$-galactosidase. Briefly, the cells were washed with $37^{\circ} \mathrm{C}$ pre-warmed PBS and fixed with $1 \mathrm{ml} 0.05 \%$ glutaraldehyde for $15 \mathrm{~min}$ at room temperature. The cells were again rinsed 3 times with PBS, followed by incubation with $1 \mathrm{mg} / \mathrm{ml} \mathrm{X}$-Gal, $1 \mathrm{mmol} / 1 \mathrm{MgCl}_{2}$ and $5 \mathrm{mmol} / 1 \mathrm{~K}_{4} \mathrm{Fe}$ $(\mathrm{CN})_{6} / \mathrm{K}_{3} \mathrm{Fe}(\mathrm{CN})_{6}$ in $200 \mu \mathrm{l} \mathrm{PBS}$ for $12 \mathrm{~h}$ at $37^{\circ} \mathrm{C}$. The cells stained for $B$-galactosidase were observed under an inverted phase contrast microscope (Nikon Eclipse TE2000-S).

RNA isolation and reverse transcription-PCR. Total RNA was extracted from capan-2 and A549 cells with TRIzol (Invitrogen) according to the manufacturer's instructions. Total RNA $(2 \mu \mathrm{g})$ in each reaction was reverse-transcribed into complementary DNA (cDNA) with oiligo(dT) primers using Moloney murine leukemia virus reverse transcriptase (Promega). The cDNAs were subjected to polymerase chain reaction under the condition of $94^{\circ} \mathrm{C}$ for $30 \mathrm{sec}, 55^{\circ} \mathrm{C}$ for $30 \mathrm{sec}$ and $72^{\circ} \mathrm{C}$ for $30 \mathrm{sec}$ for 30 cycles. Aliquots of $10 \mu \mathrm{l} \mathrm{PCR}$ reaction were analyzed by electrophoresis on $1.0 \%$ agarose gel containing ethidium bromide and the images were taken with Alpha Imager ${ }^{\mathrm{TM}} 2200$ (Alpha Innotech). The sequences of the SSTR1-5 specific primers and the lengths of each fragments amplified are shown in Table I.

Cell proliferation assay. MTT (methyl thiazolyl tetrazolium) assay was used to determine the influences of somatostatin analogues on the proliferation of capan-2 cells or A549 cells. Capan-2 or A549 cells harvested in a logarithmic growth phase were seeded on a 96-well plate at a cell density of $5 \times 10^{3}$ cells per well in $100 \mu 1$ MEM culture medium and grew overnight. The cells were then transfected overnight with Adv-LacZ or Adv-SSTR2 at MOI of 100, followed by treatment with octreotide or RC-160 at different concentrations for $4 \mathrm{~h}$ $(32,33)$. PBS was used in mock transfection. For MTT assay, the cells were incubated with $10 \mu 1$ methyl thiazolyl tetrazolium solution $(5 \mathrm{mg} / \mathrm{ml}$ in PBS) for additional $4 \mathrm{~h}$ at 
Table I. Sequences of the primers used in amplifying SSTR1-5 cDNA and the length of each fragment amplified.

\begin{tabular}{lll}
\hline Amplicon (size bp) & \multicolumn{1}{c}{ Primer set } & \multicolumn{1}{c}{ Sequence } \\
\hline SSTR1 (229 bp) & Sense primer (22 nt) & 5'-GCCAGGCGCAAAGAAGGGAGTT-3' \\
& Anti-sense primer (22 nt) & 5'-CACAGGCGACCGTGGAGAGGAG-3' \\
SSTR2 (451 bp) & Sense primer (18 nt) & 5'-CACAAGAGGGTCGAGGAG-3' \\
& Anti-sense primer (20 nt) & 5'-CATAGCGGAGGATGACATAA-3' \\
SSTR3 (355 bp) & Sense primer (23 nt) & 5'-GGACAGCAGAATGATAACCAGCC-3' \\
& Anti-sense primer (22 nt) & 5'-CGCCAGGTTGAGGATGTAGACG-3' \\
SSTR4 (301 bp) & Sense primer (24 nt) & 5'-TTCGCTACGCCAAGATGAAGACGG-3' \\
& Anti-sense primer (25 nt) & 5'-GCTGAGCACGGTGAGACAGAAGACG-3' \\
SSTR5 (315 bp) & Sense primer (25 nt) & 5'-CTGCCTGTGCTACCTGCTCATCGTG-3' \\
& Anti-sense primer (26 nt) & 5'-CTTCTGGAAGCTCTGGCGGAAGTTGT-3'
\end{tabular}

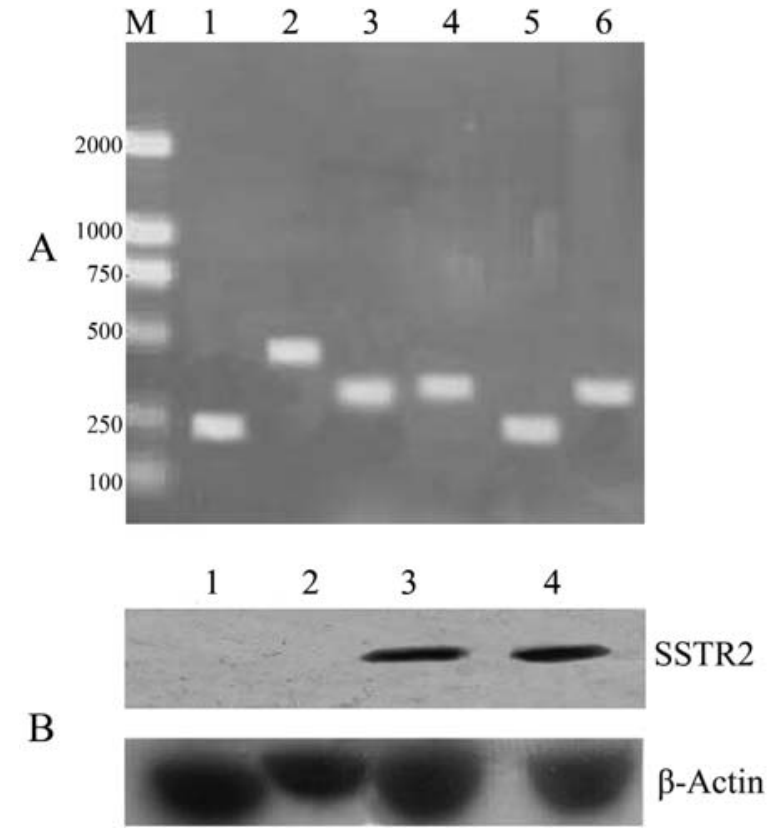

Figure 1. The expression of SSTRs in capan-2 and A549 cells. (A) The RNA expressions of all five SSTRS were analyzed by RT-PCR. SSTR1 (lane 1), SSTR2 (lane 2), SSTR4 (lane 3) and SSTR5 (lane 4) were expressed in capan-2 cells while SSTR1 (lane 5) and SSTR4 (lane 6) were expressed in A549 cells. DNA ladders were loaded in lane M. (B) The protein expression of SSTR2 was detected in capan-2 (3) and A549 cells (4) transfected with Adv-SSTR2, shown by Western blotting with anti-SSTR2. No SSTR2 proteins were detected in control capan-2 (1) cells or A549 (2) cells transfected with Adv-LacZ. The cellular B-actin is shown as an internal control.

$37^{\circ} \mathrm{C}$. Dimethyl sulfoxide (100 $\left.\mu \mathrm{l}\right)$ (Sigma) was then added to each reaction for $10 \mathrm{~min}$. The absorbance of dark-blue formazan crystals reduced by the viable cells was measured at 490 and $450 \mathrm{~nm}$ using a microplate reader (Bio-RAD 550) at room temperature. Triplication was set up for each sample.

Immunoblotting analysis. Cultured cells were collected and resuspended in lysis buffer containing $50 \mathrm{mM}$ Tris- $\mathrm{HCl}$ (pH 7.4), 100 mM KCl, 10\% glycerol, 1 mM EDTA, $1 \%$ Triton $\mathrm{X}-100$ and $1 \mathrm{mM}$ DTT protease inhibitors (Roche). Cells were lysed for $20 \mathrm{~min}$ at $4^{\circ} \mathrm{C}$ and the supernatants were collected by centrifugation at $12,000 \mathrm{x}$ g for $15 \mathrm{~min}$ at $4^{\circ} \mathrm{C}$. A total of $70 \mu \mathrm{g}$ proteins from each sample were separated by electrophoresis on $12 \%$ SDS-polyacrylamide gels and transferred to PVDF membrane (Whatman). Specific primary antibodies and horseradish peroxidase-conjugated secondary antibodies were then used for probing. The immunoblots were visualized by chemiluminescence with the ECL kit (Amersham Pharmacia) and the results were further analyzed using Alpha part II Ease (Alpha Innotech).

Statistical analysis. SPSS statistical software (version 12.0) was used for analyses. Statistical significance was determined using the analysis of variance (ANOVA). Data were deemed statistically significant at $\mathrm{P}<0.05$.

\section{Results}

Expression of SSTRs in capan-2 and A549 cells. The mRNA expressions of five SSTRs in cultured capan-2 and A549 cells were analyzed by RT-PCR. All five SSTRS except SSTR3 were expressed in capan-2 cells while only SSTR1 and SSTR4 were expressed in A549 cells (Fig. 1A). Elevated SSTR2 protein expressions were observed in capan-2 and A549 cells transfected with Adv-SSTR2, but not in the cells transfected with control adenovirus expressing $L a c Z$ in theWestern blot assay (Fig. 1B). The results suggested successful adenoviral infection and the expression of the exogenous SSTR2 gene in the in vitro transfection of the cultured cells. The endogenous SSTR2 protein was not detected in either cell line, suggesting that the protein expression of SSTR2 in these cells should be further determined or the level of endogenous protein was below the threshold of the Western blot assay in this study.

The tansfection efficacies of the adenovirus vectors. Purified Adv-LacZ (at the density of MOI of 100) was used to infect cultured capan-2 and A549 cells, respectively. The efficacy of transfection was analysed $48 \mathrm{~h}$ post-transfection. The expression of $L a c Z$ gene was visualized by $B$-gal staining. It was shown that nearly $100 \%$ transfection was obtained at MOI 

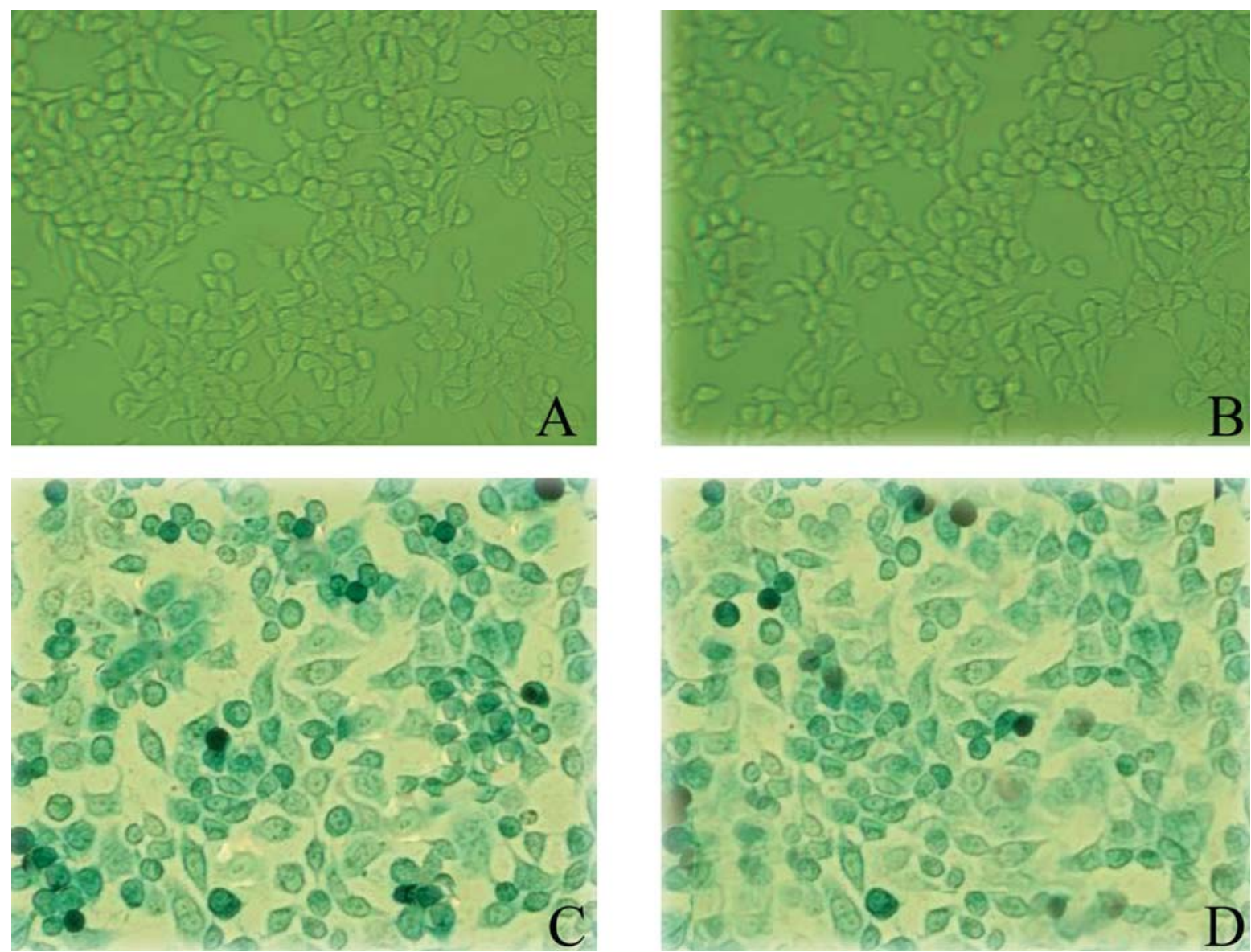

Figure 2. The efficacy of transfection of the constructed adenovirus vector in cultured cells. The transfection efficacy of the adenovirus vector was demonstrated with Adv-LacZ using B-galactosidase staining. (A) Untransfected capan-2 cells. (B) Untransfected A549 cells. (C) Adv-LacZ transfected capan-2 cells. (D) Adv-LacZ transfected A549 cells. The cells positive for B-galactosidase staining were visualized under microscope (x200) and nearly $100 \%$ transfection was shown when MOI was up to 100 . Untransfected cells showed negative $\beta$-galactosidase staining.

of 100, without showing obvious cytotoxity (Fig. 2). This amount of adenoviral vectors was used in the in vitro transfections in this study.

Octreotide inhibited the growth of experimental cancer cells in an SSTR2-dependent manner. The cultured capan-2 cells and A549 cells were treated with octreotide of different concentrations. No significant influence $(\mathrm{P}>0.05)$ on cell proliferation was observed with octreotide treatment alone, although slightly decreased growth of capan-2 cells was observed when treated with octreotide at $0.8 \mu \mathrm{g} / \mathrm{ml}$ (Fig. 3A). Compared with the Adv-LacZ transfected control cells, overexpression of SSTR2 significantly inhibited the growth of Adv-SSTR2 transfected capan-2 cells and the growth of AdvSSTR2 transfected A549 cells, up to $42 \%$ and $40 \%(\mathrm{P}<0.05)$, respectively (Fig. 3A and B). The growth of Adv-SSTR2 transfected capan-2 cells and the growth of Adv-SSTR2 transfected A549 cells were further decreased, up to $79 \%$ and $77 \%(\mathrm{P}<0.05)$, respectively, when treated with $0.8 \mu \mathrm{g} / \mathrm{ml}$ octreotide. In addition, the anti-proliferative effect of octretide observed in Adv-SSTR2 transfected cancer cells was dosedependent (Fig. 3C).

Vapreotide $R C$-160 inhibits the proliferation of experimental cancer cells with similar efficacy as octreotide. The cultured capan-2 cells and A549 cells were treated with RC-160 of different concentrations. No significant inhibition $(\mathrm{P}>0.05)$ was observed with RC-160 treatment alone in either capan-2 cells or A549 cells even at the maximum concentration (up to $8 \mathrm{mg} / \mathrm{ml}$ ) used in this study (Fig. 4A and B). However, dramatically improved anti-proliferative effects of RC-160 were observed in capan-2 and A549 overexpressing SSTR2. Compared with the untreated Adv-SSTR2 transfected control cells, the growth of Adv-SSTR2 transfected capan-2 cells and Adv-SSTR2 transfected A549 cells were further inhibited up to $80 \%$ and $75 \%(\mathrm{P}<0.05)$, respectively, when treated with $8 \mathrm{mg} / \mathrm{ml} \mathrm{RC}-160$ (Fig. 4A and B). Similar to octreotide treatment, the improved anti-proliferative effects of RC-160 observed in Adv-SSTR2 transfected cancer cells were dosedependent (Fig. 4C). No discernable difference was observed with the efficacies of the two somastatin analogues in either capan-2 or A549 cells.

SSA inhibited cell proliferation via both cytostatic and cytotoxic pathways. The cytotoxic pathway was implicated in SSTR3-mediated cell growth inhibition while the cytostatic pathway was implicated in the cell growth inhibition mediated by the other four SSTR subtypes. The potential influences of SSA/SSTR on signaling molecules in cell cycle regulation and apoptotic pathway, as well as on Ras-ERK2 signaling 

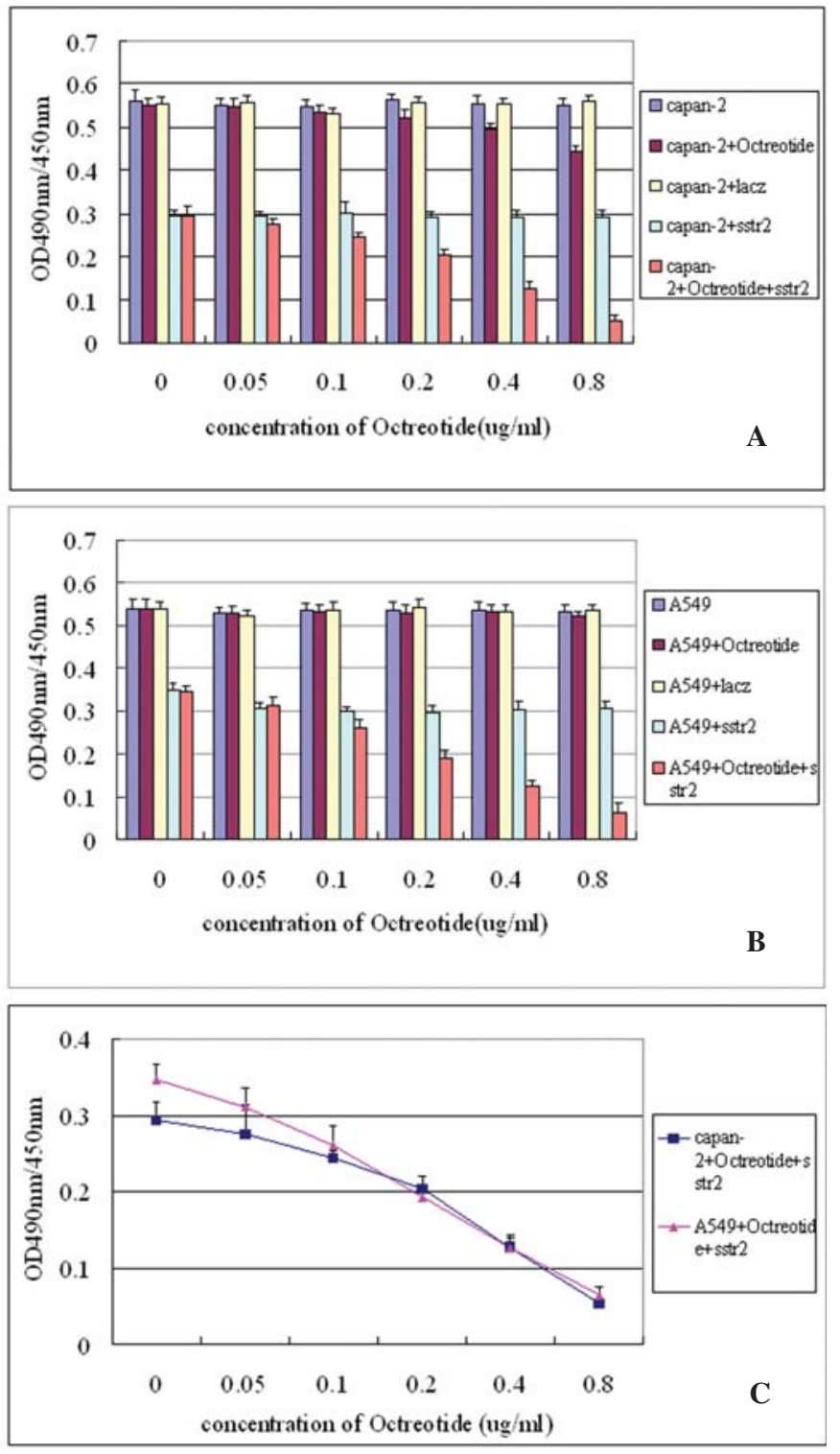

Figure 3. The influence of SSTR2 overexpression and/or Octreotide treatment on cancer cell proliferation. (A) Cell proliferation assay using capan- 2 cells. The growth of cultured capan- 2 cells was markedly inhibited by overexpression of SSTR2 (capan- $2+$ SSTR $2, \mathrm{P}<0.05$ ), compared with the control cells overexpressing B-galactosidase (capan-2 + LacZ) or the mock transfected cells (capan-2). The growth of the capan-2 cells overexpressing SSTR2 was further inhibited when treated with octreotide (capan-2 + SSTR $2+$ octreotide, $\mathrm{P}<0.05)$ at different concentrations as indicated. Octreotide treatment alone (capan- $2+$ octreotide) had a minimal influence on capan-2 cell proliferation. (B) Cell proliferation assay using A549 cells. The growth of cultured A549 cells was markedly inhibited by overexpression of SSTR2 (A549 + SSTR2, P<0.05), compared with the control cells overexpressing B-galactosidase (A549 + LacZ) or the mock transfected cells (A549). The growth of the A549 cells overexpressing SSTR2 was further inhibited when treated with octreotide (A549 + SSTR2 + octreotide, $\mathrm{P}<0.05)$ at different concentrations as indicated. Octreotide treatment alone (A549 + octreotide) had no discernable influence on A549 cell growth. (C) The anti-proliferative effect of octreotide is SSTR2-specific and dose-dependent. The growth of SSTR2-overexpressing capan-2 cells and SSTR2-overexpressing A549 cells was inhibited by octreotide in a dosedependent manner.

were further investigated using an immunoassay (Fig. 5A). The expression of the cyclin-dependent kinase inhibitors, p16 and the expression of the critical effector of both extrinsic
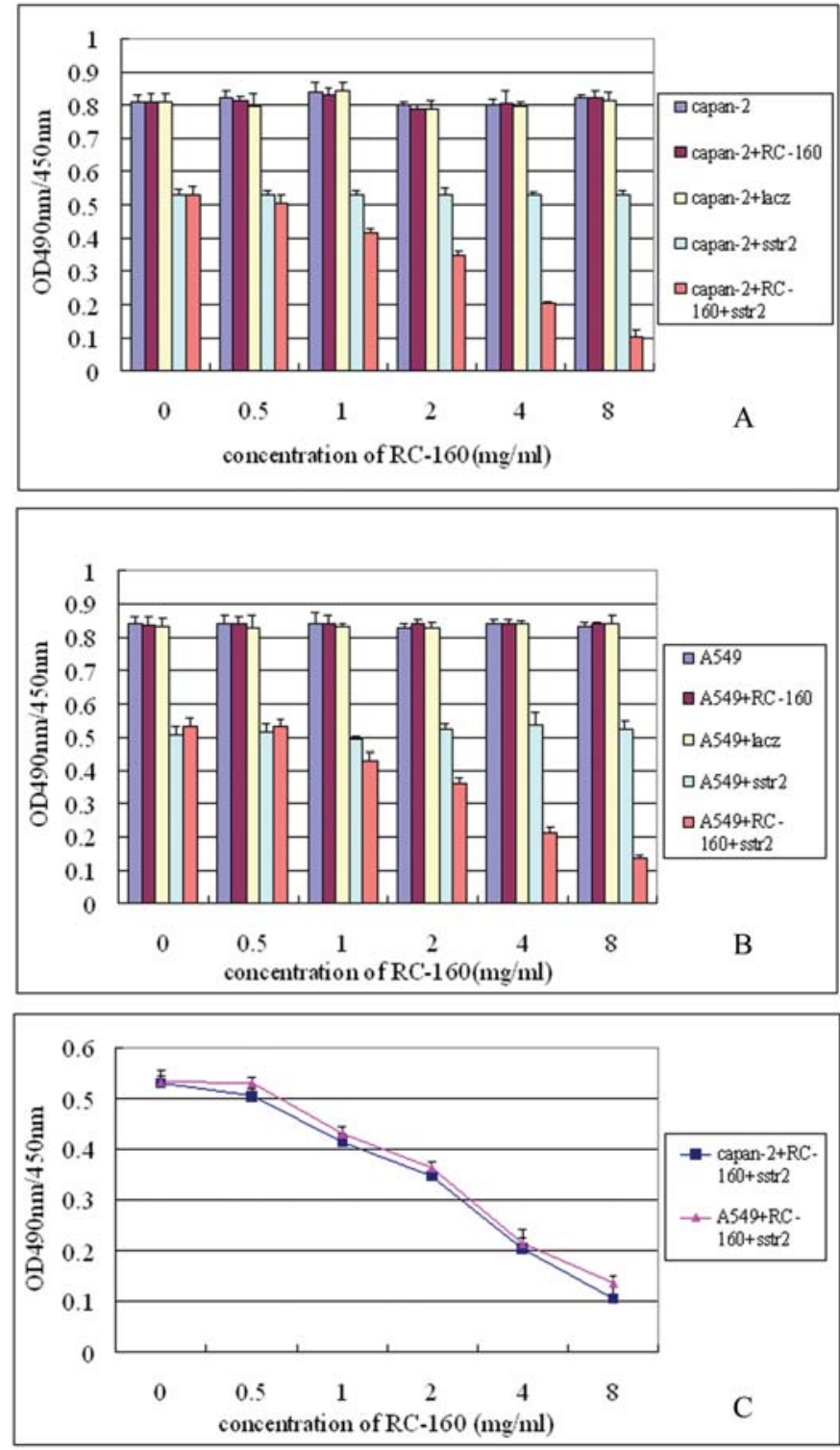

Figure 4. The influence of SSTR2 overexpression and/or RC-160 treatment on cancer cell proliferation. (A) Cell proliferation assay using capan-2 cells. The growth of cultured capan-2 cells was markedly inhibited by overexpression of SSTR2 (capan-2 + SSTR2, P<0.05), compared with the control cells overexpressing $\beta$-galactosidase (capan-2 + LacZ) or the mock transfected cells (capan-2). The growth of the capan- 2 cells overexpressing SSTR2 was further inhibited when treated with RC-160 (capan-2 + SSTR2 $+\mathrm{RC}-160, \mathrm{P}<0.05)$ at different concentrations as indicated. No discernable influence on capan-2 cell proliferation was observed with RC-160 treatment alone (capan-2 + RC-160). (B) Cell proliferation assay using A549 cells. The growth of cultured A549 cells was markedly inhibited by overexpression of SSTR2 (A549 + SSTR2, P<0.05), compared with the control cells overexpressing $\beta$-galactosidase (A549 + LacZ) or the mock transfected cells (A549). The growth of the A549 cells overexpressing SSTR2 was further inhibited when treated with RC-160 (A549 + SSTR2 + RC-160, $\mathrm{P}<0.05)$ at different concentrations as indicated. RC-160 treatment alone (A549 + RC-160) had no discernable influence on the proliferation of A549 cells. (C) The anti-proliferative effect of RC-160 is SSTR2-specific and dose-dependent. The proliferation of SSTR2-overexpressing capan-2 cells and SSTR2-overexpressing A549 cells was inhibited by RC-160 in a dosedependent manner.

and intrinsic apoptotic pathway, caspase-3, were upregulated in capan-2 cells overexpressing SSTR2 as well as in the AdvSSTR2 transfected capan-2 cells treated with octreotide/ 


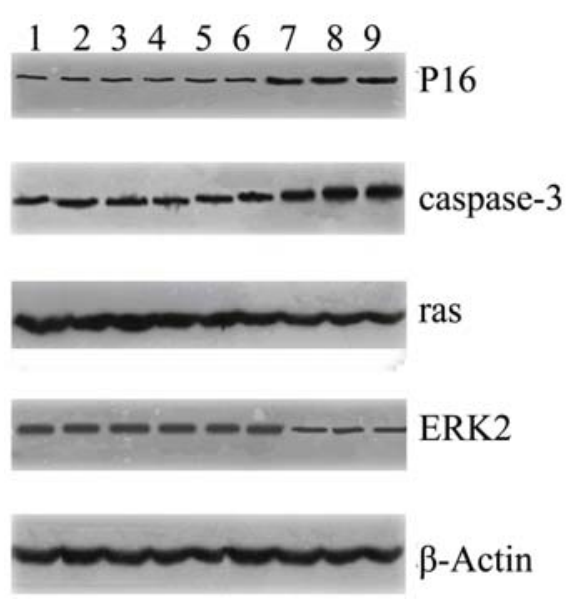

B
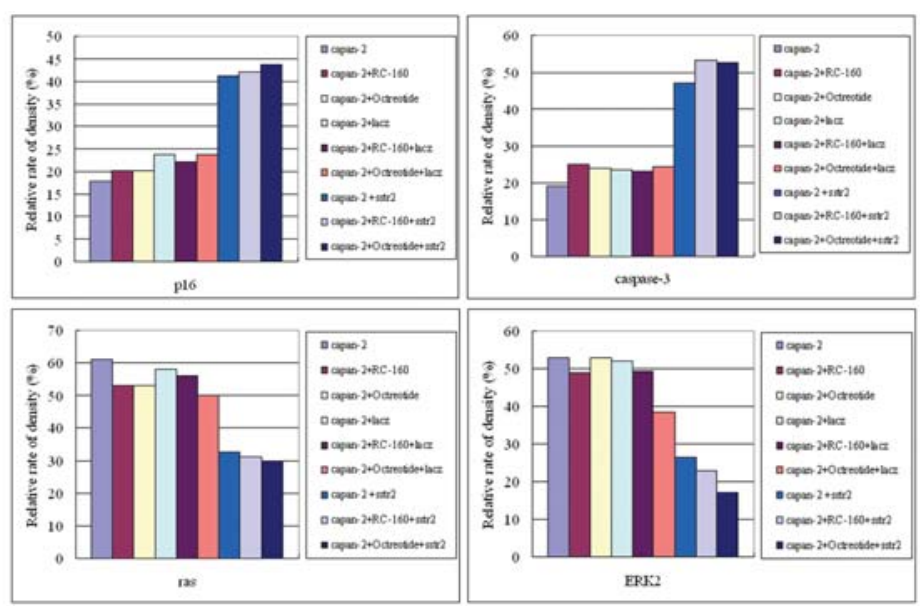

Figure 5. SSA/SSTR2 inhibited cancer cell proliferation via multiple pathways. (A) The influences of SSA/SSTR2 signaling on components in cytostatic and cytotoxic pathways were analyzed in experimental cancer cells using Western blot assay. Total cellular proteins of untransfected capan-2 cells (lane 1), capan-2 cells treated with RC-160 (lane 2), capan-2 cells treated with octreotide (lane 3), capan-2 cells transfected with Adv-LacZ (lane 4), Adv-lacZ transfected capan-2 cells treated with RC-160 (lane 5), Adv-LacZ transfected capan-2 cells treated with octreotide (lane 6), Adv-SSTR2 transfected capan-2 cells (lane 7), Adv-SSTR2 transfected capan-2 cells treated with RC-160 (lane 8) and Adv-SSTR2 transfected capan-2 cells treated with octreotide (lane 9) were separated on $12 \%$ SDS-PAGE and probed against the indicated proteins, respectively. (A) $\beta$-actin was used as an internal control. (B) Compared with the untransfected capan-2 cells (capan-2) or with the Adv-LacZ transfected control capan-2 cells (capan-2 + LacZ), the expression of p16 and caspase-3 was dramatically increased in Adv-SSTR2 transfected capan-2 cells (capan-2 + SSTR2) and in Adv-SSTR2 transfected capan-2 cells treated with RC-160 (capan-2 + SSTR2 + RC-160) or octreotide (capan-2 + SSTR2 + octreotide). By contrast, the intracellular level of oncogenic Ras and ERK2 was significantly downregulated in capan-2 cells overexpressing SSTR2 (capan-2 + SSTR2) and in Adv-SSTR2 transfected capan-2 cells treated with RC-160 (capan-2 + SSTR2 + RC-160) or octreotide (capan-2 + SSTR2 + octreotide). Treatment with octreotide (capan-2 + octreotide) or RC-160 (capan-2 + RC-160) alone had a minimal impact on the expression of these signaling molecules.

RC-160 (Fig. 5B). It indicated that the activated SSTR2 inhibited cell proliferation via cell cycle arrest and via promoting apoptosis. By contrast, the expressions of the oncogenic Ras and ERK2 were decreased in Adv-SSTR2 transfected capan-2 cells as well as in Adv-SSTR2 transfected capan-2 cells treated with octreotide/RC160, compared with the Adv-LacZ transfected controls. In line with the data of the cell proliferation assay, octreotide/RC-160 treatment alone did not result in noticeable changes in these gene expressions. Similar results were also observed using A549 cells (data not shown).

\section{Discussion}

SSTRs express ubiquitously in embryos and adult tissues in a subtype-selective manner. High levels of SSTR2 expression have been seen in normal tissues as well as in most of human tumors, including pituitary tumors, insulinomas, breast cancers and pancreatic cancers. These tissues usually feature SSTR isotypes other than SSTR2 with relatively lower levels (27). Due to the anti-proliferative effects of SSTR signaling, somatostatin and its analogues have been commonly used as a complimentary treatment in post-surgical medication for cancers. In contrast to the high expectations, many clinical trials reported insensitivity to the treatment with somatostatin and its analogues $(34,35)$. The lack of benefits was believed to be a consequence of the loss of expression of SSTRS, particularly SSTR2, in these patients, although hardly any of these clinical trials had been screened for the SSTR2 expression (36).

The results in this study demonstrated that despite the endogenous SSTR2 expression, somatostatin analogue treatment alone has very limited influence on cancer cell proliferation, in line with the poor outcomes reported in some cancer patients who received somatostatin analogue treatment only. However, overexpression of SSTR2 in our experimental cancer cells significantly inhibited cell proliferation and improved their response to somatostatin analogues. These findings indicate that it is the amount of intracellular SSTR2 that pulls the trigger. In addition, SSTR2 gene transfer, which has been considered for SSTR2-negative tumors, can also be a promising candidate for cancer gene therapy for SSTR2-positive tumors.

We further investigated the possible mechanisms of the anti-tumor effects. SSTR2 has been shown to inhibit cell proliferation via cytostatic actions by increasing the expression of the cyclin-dependent protein kinase inhibitors in a MAPKdependent manner in previous studies (37). In this research, we showed that the overexpression of SSTR2 resulted in up-regulation of the cyclin-dependent kinase (CDK2, CDK4 and CDK6) inhibitor, p16, which in turn, was able to cease the $\mathrm{G} 1 / \mathrm{S}$ phase transition and stop the cell cycle progress. Also, we suggested that the apoptotic pathway might play a pivotal role in the SSTR2-mediated inhibition of cell proliferation by showing that the intracellular level of caspase-3, the critical effector of intrinsic and extrinsic apoptotic pathway, was upregulated in SSTR2 transfected cancer cells. It indicated that SSTR2 signaling could inhibit proliferation via cytostatic and cytotoxic actions. The cytostatic and cytotoxic action observed could be the indirect effects mediated by other SSTR subtypes since heteromeric interactions between SSTR subtypes have been reported for SSTR2/SSTR5 (38). However, given the similar degree of inhibition in proliferation observed with Adv-SSTR2 
transfected capan-2 and A549 cells, we suggested that the heterodimerization of SSTR2/SSTR5 might not be necessary in SSTR2-mediated anti-proliferation since A549 cells were negative of endogenous SSTR5 expression. Nonetheless, recent research suggested that SSTR5 might play a role in mediating long-term response to octreotide while SSTR2 mediated the short-term response (39). Further investigations using SSTR2 and SSTR5 selective antagonists will help to understand the interplay between SSTR2 and SSTR5 signalings.

The small GTPase, Ras, is another signaling molecule that has usually been found overexpressed in most human tumors. Activated Ras activates Raf and in turn, activates MEK and contributes to substantial tumor cell growth (40). ERK promotes cell growth by enhancing the Ras-MEK pathway as well as by accelerating cytoplasmic $\beta$-catenin accumulation in Wnt pathway (40). Free cytoplasmic $\beta$-catenin relocates into nucleus and serves as a cofactor with $\mathrm{T}$ cell factor/lymphoid enhancer factor to regulate target gene expression (41). The expression of RAS and ERK2 was downregulated in our SSTR2 transfected tumors, suggesting that SSTR2 interferes with the essential oncogenic RAS-ERK signaling cascade.

Collectively, the findings in this study suggested that SSTR2, as a very promising candidate for cancer gene therapy, might be applied to a wide spectrum of cancers that have different profiles of endogenous SSTR expressions. Also, the insensitivities of certain tumors to somatostatin analogue treatment could be remarkably improved by exogenous SSTR2 expression in these tumors. The anti-proliferative effects of SSTR2 signaling involved multiple pathways, including cytostatic and cytotoxic actions. Further investigations utilizing subtype-specific somatostatin analogues on tumors with different endogenous SSTR expressions will lead to a better understanding of the mechanisms of the anti-tumor effects of SSTRs.

\section{Acknowledgements}

This study was sponsored by the National Natural Science Foundation of China (90608024) and partly supported by the setup grant of Jinan University (51207016).

\section{References}

1. Patel YC, Greenwood MT, Panetta R, Demchyshyn H, Niznik HB and Srikant CB: The somatostatin receptor family: a minireview. Life Sci 57: 1249-1265, 1995.

2. Corness JD, Demchyshyn LL, Seeman P, et al: A human somatostatin receptor (SSTR3), located on chromosome 22, displays preferential affinity for somatostatin-14 like peptides. FEBS Lett 321: 279-284, 1993.

3. Bruno JF, Xu Y, Song J and Berelowitz M: Molecular cloning and functional expression of a brain-specific somato-statin receptor. Proc Natl Acad Sci USA 89: 11151-11155, 1992.

4. Demchyshyn LL, Srikant CB, Sunahara RK, et al: Cloning and expression of a human somatostatin-14-selective receptor variant (somatostatin receptor 4) located on chromosome 20. Mol Pharmacol 43: 894-901, 1993.

5. Carroll O, Lolait AM, Konig SJ and Mahan MLC: Molecular cloning and expression of a pituitary somatostatin receptor with preferential affinity for somatostatin-28. Mol Pharmacol 42: 939-946, 1992.

6. Panetta R, Greenwood MT, Warszynska A, et al: Molecular cloning, functional characterization, and chromosomal localization of a human somatostatin receptor (somatostatin receptor type 5) with preferential affinity for somatostatin-28. Mol Pharmacol 45: 417-427, 1994.
7. Kumar U, Sasi R, Suresh S, et al: Subtype-selective expression of the five somatostatin receptors (hSSTR1-5) in human pancreatic islet cells: A quantitative double-label immunohistochemical analysis. Diabetes 48: 77-85, 1999.

8. Breder CD, Yamada YY, Yasuda K, Seino S, Saper CB and Bell GI: Differential expression of somatostatin receptor subtypes in brain. Neuroscience 12: 3920-3934, 1992.

9. Le Romancer M, Cherifi Y, Levasseur S, et al: Messenger RNA expression of somatostatin receptor subtypes in human and rat gastric mucosae. Life Sci 58: 1091-1098, 1996.

10. Rohrer L, Ranulf F, Bruns C, Buettner R, Hofstaedter F and Schule R: Cloning and characterization of a fourth human somatostatin receptor. Proc Natl Acad Sci USA 90: 4196-4200, 1993.

11. Yamada Y, Post SR, Wang K, Tager HS, Bell GI and Seino S: Cloning and functional characterization of a family of human and mouse somatostatin receptors expressed in brain, gastrointestinal tract, and kidney. Proc Natl Acad Sci USA 89: 251-255, 1992.

12. Hofland LJ and Lamberts SW: Somatostatin receptors and disease: role of receptor subtypes. Baillieres Clin Endocrinol Metab 10: 163-176, 1996.

13. Taboada GF, Luque RM, Bastos W, et al: Quantitative analysis of somatostatin receptor subtype (SSTR1-5) gene expression levels in somatotropinomas and non-functioning pituitary adenomas. Eur J Endocrinol 156: 65-74, 2007.

14. Janson ET, Gobl A, Kälkner KM and Oberg K: A comparison between the efficacy of somatostatin receptor scintigraphy and that of in situ hybridization for somatostatin receptor subtype 2 messenger RNA to predict therapeutic outcome in carcinoid patients. Cancer Res 56: 2561-2565, 1996.

15. Kumar M, Liu ZR, Thapa L, Wang DY, Tian R and Qin RY: Mechanisms of inhibition of growth of human pancreatic carcinoma implanted in nude mice by somatostatin receptor subtype2. Pancreas 29: 141-151, 2004.

16. Vernejoul F, Faure P, Benali N, et al: Antitumor effect of in vivo somatostatin receptor subtype 2 gene transfer in primary and metastatic pancreatic cancer models. Cancer Res 62: 6124-6131, 2002.

17. Celinski SA, Fisher WE, Amaya F, Wu YQ, Yao Q, Youker KA and $\mathrm{Li} \mathrm{M}$ : Somatostatin receptor gene transfer inhibits established pancreatic cancer xenografts. J Surg Res 115: 41-47, 2003.

18. Patel YC: Somatostatin and its receptor family. Front Neuroendocrinol 20: 157-198, 1999.

19. Lamberts SWJ, Krenning EP and Reubi J-C: The role of somatostatin and its analogs in the diagnosis and treatment of tumors. Endocr Rev 12: 450-482, 1991.

20. Lamberts SWJ, Van Der Lely A-J and de Herder WW: Drug therapy: Octreotide. N Eng J Med 334: 246-254, 1996.

21. Weckbeker G, Raulf F, Stolz B and Bruns C: Somatostatin analogs for diagnosis and treatment of cancer. Pharmac Ther 60: 245-264, 1993.

22. Kvols LK and Woltering EA: Role of somatostatin analogs in the clinical management of non-neuroendocrine solid tumors. Anticancer Drugs 17: 601-608, 2006.

23. Horiguchi K, Yamada M, Umezawa R, et al: Somatostatin receptor subtypes mRNA in TSH secreting pituitary adenomas: a case showing a dramatic reduction in tumor size during short octreotide treatment. Endocr J 54: 371-378, 2007.

24. Pawlikowski M and Melen-Mucha G: Somatostatin analogs from new molecules to new applications. Curr Opin Pharmacol 4: 608-613, 2004.

25. Hofland LJ, van der Hoek J, Feelders R, van der Lely AJ, de Herder W and Lamberts SW: Pre-clinical and clinical experiences with novel somatostatin ligands:advantages, disadvantages and new prospects. Endocrinol Invest 28: 36-42, 2005.

26. Petersenn S: Efficacy and limits of somatostatin analogs. Endocrinol Invest 28: 53-57, 2005.

27. Guillermet-Guibert J, Lahlou H, Cordelier P, Bousquet C, Pyronnet S and Susini C: Physiology of somatostatin receptors. Endocrinol Invest 28: 5-9, 2005.

28. Cattaneo AG, Taylor JE, Culler MD, Nisoli E and Vicentini LM: Selective stimulation of somatostatin receptor subtypes: differential effects on Ras/MAP kinase pathway and cell proliferation in human neuroblastoma cells. FEBS Lett 481: 271-276, 2000.

29. Sharma K, Patel YC and Srikant CB: Subtype-selective induction of wild-type p53 and apoptosis, but not cell cycle arrest, by human somatostatin receptor 3. Mol Endocrinol 10: 1688-1696, 1996. 
30. Rocheville M, Lange DC, Kumar U, Patel SC, Patel RC and Patel YC: Receptors for dopamine and somatostatin: formation of hetero-oligomers with enhanced functional activity. Science 288: 154-157, 2000.

31. Reubi JC, Schär JC, Waser B, Wenger S, Heppeler A, Schmitt JS and Mäcke HR: Affinity profiles for human somatostatin receptor subtypes SST1-SST5 of somatostatin radiotracers selected for scintigraphic and radiotherapeutic use. Eur J Nucl Med 27: 273-282, 2002.

32. Liu HL, Huo L and Wang L: Octreotide inhibits proliferation and induces apoptosis of hepatocellular carcinoma cells. Acta Pharmacol Sin 25: 1380-1386, 2004.

33. Buscail L, Delesque N, Esteve JP, et al: Stimulation of tyrosine phosphatase and inhibition of cell proliferation by somatostatin analogues: Mediation by human somatostatin receptor subtypes SSTR1 and SSTR2. Proc Natl Acad Sci USA 91: 2315-2319, 1994.

34. Klijn JG, Hoff AM, Planting AS, et al: Treatment of patients with metastatic pancreatic and gastrointestinal tumours with the somatostatin analogue Sandostatin: a phase II study including endocrine effects. Br J Cancer 62: 627-630, 1990.

35. Kohlfuerst S, Igerc I, Gallowitsch HJ, Gomez I, Kresnik E, Matschnig S and Lind P: Is there a role for sandostatin treatment in patients with progressive thyroid cancer and iodine-negative but somatostatin-receptor-positive metastases? Thyroid 16 : 1113-1119, 2006.
36. Taboada GF, Luque RM, Neto LV, et al: Quantitative analysis of somatostatin receptor subtypes (1-5) gene expression levels in somatotropinomas and correlation to in vivo hormonal and tumor volume responses to treatment with octreotide LAR. Eur J Endocrinol 158: 295-303, 2008.

37. Stirnweiss J, Hartrodt B, Greksch G, Stürzebecher U, Böhmer FD, Neubert K and Liebmann C: Tyr-c[D-Orn-Tyr(Bzl)-Pro-Gly]: a novel antiproliferative acting somatostatin receptor agonist with mu-opioid receptor-sensitizing properties. Br J Pharmacol 140: 13-22, 2003.

38. Ren SG, Taylor J, Dong J, Yu R, Culler MD and Melmed S: Functional association of somatostatin receptor subtypes 2 and 5 in inhibiting human growth hormone secretion. J Clin Endocrinol Metab 88: 4239-4245, 2003.

39. Yoshihara A, Isozaki O, Hizuka N, et al: Expression of type 5 somatostatin receptor in TSH-secreting pituitary adenomas: a possible marker for predicting long-term response to octreotide therapy. Endocr J 54: 133-138, 2007.

40. Yang JY, Zong CS, Xia W, et al: ERK promotes tumorigenesis by inhibiting FOXO3a via MDM2-mediated degradation. Nat Cell Biol 10: 138-147, 2008.

41. Nelson WJ and Nusse R: Convergence of Wnt, beta-catenin, and cadherin pathways. Science 303: 1483-1487, 2004. 